\title{
The role of retrospective weather forecasts in developing daily forecasts of nutrient loadings over the southeast US
}

\author{
J. $\mathrm{Oh}^{1}$, T. Sinha ${ }^{2}$, and A. Sankarasubramanian ${ }^{2}$ \\ ${ }^{1}$ Department of Geological Sciences, University of North Carolina, Chapel Hill, NC 27599-3315, USA \\ ${ }^{2}$ Department of Civil, Construction and Environmental Engineering, North Carolina State University, Raleigh, NC \\ 27695-5908, USA
}

Correspondence to: T. Sinha (tsinha@ncsu.edu)

Received: 22 October 2013 - Published in Hydrol. Earth Syst. Sci. Discuss.: 20 December 2013

Revised: 19 June 2014 - Accepted: 19 June 2014 - Published: 6 August 2014

\begin{abstract}
It is well known in the hydrometeorology literature that developing real-time daily streamflow forecasts in a given season significantly depends on the skill of daily precipitation forecasts over the watershed. Similarly, it is widely known that streamflow is the most important predictor in estimating nutrient loadings and the associated concentration. The intent of this study is to bridge these two findings so that daily nutrient loadings and the associated concentration could be predicted using daily precipitation forecasts and previously observed streamflow as surrogates of antecedent land surface conditions. By selecting 18 relatively undeveloped basins in the southeast US (SEUS), we evaluate the skill in predicting observed total nitrogen (TN) loadings in the Water Quality Network (WQN) by first developing the daily streamflow forecasts using the retrospective weather forecasts based on K-nearest neighbor (K-NN) resampling approach and then forcing the forecasted streamflow with a nutrient load estimation (LOADEST) model to obtain daily TN forecasts. Skill in developing forecasts of streamflow, TN loadings and the associated concentration were computed using rank correlation and RMSE (root mean square error), by comparing the respective forecast values with the WQN observations for the selected 18 Hydro-Climatic Data Network (HCDN) stations. The forecasted daily streamflow and TN loadings and their concentration have statistically significant skill in predicting the respective daily observations in the WQN database at all 18 stations over the SEUS. Only two stations showed statistically insignificant relationships in predicting the observed nitrogen concentration. We also found that the skill in predicting the observed TN loadings increases with the increase in drainage area, which in-
\end{abstract}

dicates that the large-scale precipitation reforecasts correlate better with precipitation and streamflow over large watersheds. To overcome the limited samplings of TN in the WQN data, we extended the analyses by developing retrospective daily streamflow forecasts over the period 19792012 using reforecasts based on the K-NN resampling approach. Based on the coefficient of determination $\left(R_{Q \text {-daily }}^{2}\right)$ of the daily streamflow forecasts, we computed the potential skill $\left(R_{\mathrm{TN} \text {-daily }}^{2}\right)$ in developing daily nutrient forecasts based on the $R^{2}$ of the LOADEST model for each station. The analyses showed that the forecasting skills of TN loadings are relatively better in the winter and spring months, while skills are inferior during summer months. Despite these limitations, there is potential in utilizing the daily streamflow forecasts derived from real-time weather forecasts for developing daily nutrient forecasts, which could be employed for various adaptive nutrient management strategies for ensuring better water quality.

\section{Introduction}

Anthropogenic interventions of biogeochemical cycles have resulted in increased nutrient loadings in streams over the past few decades (Galloway et al., 1995; Caraco and Cole, 1999). Continuous concerns about water quality degradation have resulted in the development of active water quality management programs such as total maximum daily load allocation (TMDL) as well as establishment of policy instruments related to water quality trading. Of particular interest is the total nitrogen (TN) loadings, whose contribution from the 
land surface to the North Atlantic Ocean has increased from 5 to 20-fold in comparison to the pre-industrial/natural level (Howarth et al., 1996). Nitrate levels have tripled in major rivers over the northeastern US since the 1900s, while nitrate concentration has doubled in the Mississippi River basin since 1965 (Turner and Rabalais, 1991; Howarth et al., 1996; Vitousek et al., 1997; Goolsby and Battaglin, 2001).

Excess nitrogen results in overproduction of phytoplankton, which in turn causes anoxic conditions and eutrophication in lakes and coastal regions (Vitousek et al., 1997; Pinckney et al., 1999). Such eutrophication, due to natural and anthropogenic nitrogen sources, is an important water quality degradation issue, which ranges from small streams (Duff et al., 2008) to large water bodies such as the Gulf of Mexico (e.g., Bricker et al., 1999; Alexander et al., 2000; Rabalais et al., 2002; Alexander and Smith, 2006). There have been several efforts to reduce nitrogen loadings to streams but such programs are often too costly. For example, the North Carolina Department of Energy and Natural Resources (DENR) have spent several billion dollars in nutrient management of Falls Lake in the Neuse River to control total nitrogen loadings under permissible range (North Carolina DENR). But availability of data on total nitrogen is limited, with concentration being measured on a noncontinuous basis. Studies have tried to overcome these limitations by using the long available records of streamflow, since both instream nutrient concentration and loadings primarily depend on streamflow variability (Borsuk et al., 2004; Paerl et al., 2006; Lin et al., 2007) and antecedent flow conditions (Vecchia, 2003; Alexander and Smith, 2006). Various nutrient simulation models have been developed to estimate loadings using semi-distributed hydrologic models (e.g., WASP, HSPF, SWAT, GWLF) or statistical models (e.g., LOADEST). Both types of models are typically implemented under a simulation mode by using observed meteorological forcings to estimate nitrogen loadings. Similarly, considerable progress has been made in developing daily streamflow forecasts using statistical models, e.g., parametric models (Rajagopalan and Lall, 1999; Anderson et al., 2002; Salas and Lee, 2010), and semi-distributed watershed models (e.g., Clark and Hay, 2004; Mcenery et al., 2005; Georgakakos et al., 2010). Developing daily streamflow forecasts over a large region using semi-distributed models requires intensive spatial data (e.g., topography, land cover, soils) and computational resources, hence, we employed a semi-parametric approach in this study. In particular, we employed the K-nearest neighbor (K-NN) semi-parametric scheme to develop daily streamflow forecasts contingent on updated climate forecasts since it can capture non-linear relationships that are typically observed in daily streamflow data (Salas and Lee, 2010). The K-NN scheme has been widely used in hydrologic studies (Rajagopalan and Lall, 1999; Prairie et al., 2006; Sharif and Burn, 2006). Although daily streamflow forecasts could be developed with reasonable skill, there is a gap in linking those forecasts to the development of daily nutrient load- ing forecasts. Furthermore, several studies have utilized antecedent streamflows as surrogates of initial catchment conditions (e.g., Chiew and McMohan, 2002; Piechota et al., 2001; Wang et al., 2009) including 3-day average streamflow conditions (Majumdar and Kumar, 1990; Srinivas and Srinivasan, 2000; Cigizoglu, 2003). In our analysis, the maximum auto-correlation between observed streamflow and the previous-day streamflow occurred with a lag of 3 days for the selected sites (figure not shown). Given that skillful forecasts of daily nutrient loadings could be utilized in improving instream water quality, we intend to investigate the potential in forecasting daily nutrient loadings conditional on daily precipitation forecasts and previously observed streamflow as surrogates of antecedent moisture conditions for 18 watersheds that are minimally affected by anthropogenic interventions over the southeast US (SEUS).

The manuscript is organized as follows: Sect. 2 details the data sources for daily streamflow, observed daily total nitrogen samplings and retrospective daily precipitation forecasts that were utilized in the study. Following that, we describe the methodology behind the development of daily streamflow and nutrient loading forecasts. Section 4 provides the results on the skill in predicting the observed nutrient loadings over the selected 18 watersheds. Finally, in Sect. 5, we summarize the salient findings and conclusions arising from the study.

\section{Data description}

This section outlines the streamflow, Water Quality Network (WQN), and retrospective weather forecasts associated with the development of total nitrogen forecasts over the SEUS.

\subsection{HCDN streamflow database}

Given that the intent of the study is to associate daily nutrient loadings with daily precipitation forecasts, we focus our analysis on 18 undeveloped basins over the SEUS from the Hydro-Climatic Data Network (HCDN) database (Slack et al., 1993). Figure 1 shows the location of $18 \mathrm{HCDN}$ stations and Table 1 provides the list of the 18 stations considered in this study along with their drainage areas. Daily streamflow records in the HCDN basins is purported to be relatively free of anthropogenic influences such as upstream storage and groundwater pumping and the accuracy ratings of these records are at least "good" according to United States Geological Survey (USGS) standards. Since the streamflow data $(Q)$ in the HCDN database is available only up to 1988 , we extended records up to 2009 based on the USGS historical daily streamflow database.

\subsection{Weather forecasts database}

We employed retrospective weather forecasts from the National Oceanic and Atmospheric Administration (NOAA) to forecast daily streamflow at multiple sites in the SEUS 
Table 1. Baseline information for the 18 selected stations. Percentage land use area under urban and agriculture are calculated based on the 2001 USGS NLCD data. Values in the parentheses in the last column show the total number of daily total nitrogen loadings and concentration samplings available for each station.

\begin{tabular}{cclrrrr}
\hline $\begin{array}{c}\text { Station } \\
\text { index }\end{array}$ & $\begin{array}{c}\text { Station } \\
\text { number }\end{array}$ & Station name & $\begin{array}{r}\text { Drainage } \\
\text { area }\left(\mathrm{km}^{2}\right)\end{array}$ & $\begin{array}{r}\text { \% Area under } \\
\text { agriculture }\end{array}$ & $\begin{array}{r}\text { \% Area } \\
\text { under urban }\end{array}$ & $\begin{array}{r}\text { Number of years } \\
\text { (\# of daily obs.) }\end{array}$ \\
\hline 1 & 2047000 & Nottoway River near Sebrell, VA & 3732.17 & 16.9 & 5.0 & $17(95)$ \\
2 & 2083500 & Tar River at Tarboro, NC & 5653.94 & 28.9 & 8.0 & $22(152)$ \\
3 & 2126000 & Rocky River near Norwood, NC & 3553.46 & 28.7 & 22.8 & $14(65)$ \\
4 & 2176500 & Coosawhatchie River near Hampton, SC & 525.77 & 23.9 & 6.8 & $13(100)$ \\
5 & 2202500 & Ogeechee River near Eden, GA & 6863.47 & 23.5 & 5.0 & $20(141)$ \\
6 & 2212600 & Falling Creek near Juliette, GA & 187.00 & 0.6 & 2.4 & $14(56)$ \\
7 & 2228000 & Satilla River at Atkinson, GA & 7226.07 & 20.4 & 7.6 & $20(123)$ \\
8 & 2231000 & St. Marys River near Macclenny, FL & 1812.99 & 3.8 & 5.9 & $14(108)$ \\
9 & 2321500 & Santa Fe River at Worthington Springs, FL & 1489.24 & 12.3 & 6.4 & $21(82)$ \\
10 & 2324000 & Steinhatchee River near Cross City, FL & 906.50 & 0.8 & 4.8 & $19(92)$ \\
11 & 2327100 & Sopchoppy River near Sopchoppy, FL & 264.18 & 0.0 & 1.0 & $22(125)$ \\
12 & 2329000 & Ochlockonee River near Havana, FL & 2952.59 & 28.6 & 6.9 & $22(133)$ \\
13 & 2358000 & Apalachicola River at Chattahoochee, FL & 44547.79 & 22.5 & 9.8 & $23(152)$ \\
14 & 2366500 & Choctawhatchee River near Bruce, FL & 11354.51 & 19.6 & 5.6 & $21(119)$ \\
15 & 2368000 & Yellow River at Milligan, FL & 1616.15 & 17.6 & 6.5 & $21(123)$ \\
16 & 2375500 & Escambia River near Century, FL & 9885.98 & 12.5 & 4.8 & $22(145)$ \\
17 & 2479155 & Cypress Creek near Janice, MS & 136.23 & 0 & 0.9 & $16(54)$ \\
18 & 2489500 & Pearl River near Bogalusa, LA & 17023.99 & 15.2 & 6.8 & $12(57)$ \\
\hline
\end{tabular}

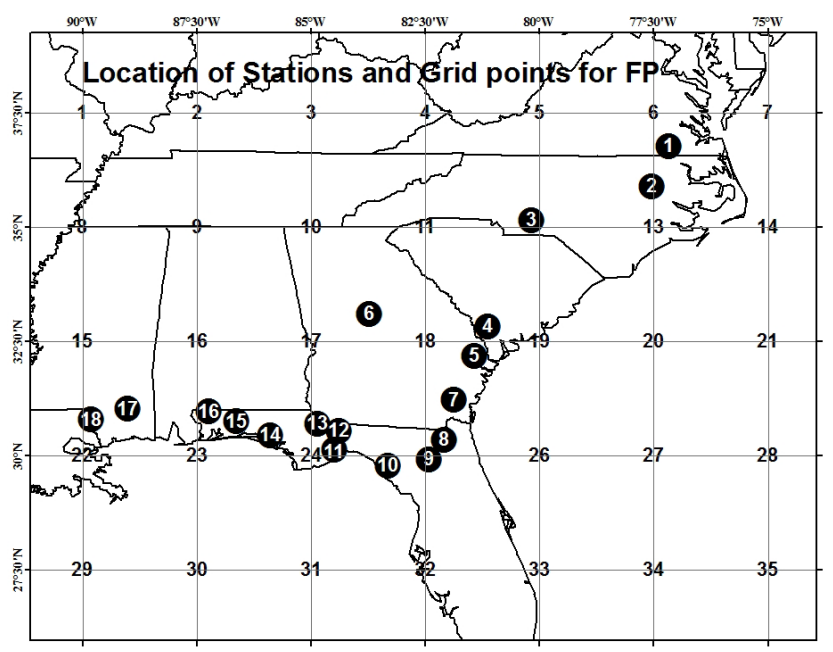

Figure 1. Locations of 18 water quality monitoring stations and grids of forecasted precipitation from NOAA's reforecast model.

(Hamill et al., 2004, 2006). NOAA's Earth System Research Laboratory/Physical Science Division (ESRL/PSD) reforecast project provides daily precipitation forecasts from the Global Forecast System (GFS) model, which was formerly called the Medium-Range Forecast Model (MRF). The GFS has 28 sigma (pressure) levels and a T62 spatial resolution ( $\sim 200 \mathrm{~km}$ grid size), which represents physical processes to estimate atmospheric forcings such as winds, temperature, precipitation, and geopotential heights at different pres- sure levels (Hamill et al., 2006). Fifteen ensemble forecasts are obtained by initializing different atmospheric states of the GFS model every day. The control run is initialized by the National Center for Environmental Prediction (NCEP)National Center for Atmospheric Research (NCAR) reanalysis data (Kalnay et al., 1996), while the other 14 ensemble members use a set of 7 bred pairs of initial conditions (Toth and Kalnay, 1997), which are re-centered each day on the reanalysis initial condition. In this study, we make use of daily precipitation reforecasts from the GFS model consists of 15 ensemble members, up to 15 days in advance, starting from 1979 to present. We considered the ensemble mean of daily precipitation forecasts in order to forecast daily streamflow and daily total nitrogen loadings for the selected watersheds.

\subsection{Water Quality Monitoring Network (WQN) database}

The USGS provides national and regional descriptions of stream water quality conditions in the Water Quality Monitoring Network (WQN) across the nation (Alexander et al., 1998). The WQN database is comprised of water quality data from the USGS monitoring networks for large watersheds (National Stream Quality Accounting Network, NASQAN) as well as watersheds that are minimally developed (Hydrologic Benchmark Network, HBN). We used the observed daily concentrations of total nitrogen (TN) for the 18 stations in the SEUS from the WQN database. By selecting watersheds from the HCDN database, we basically ensure that the streamflow is minimally affected by anthropogenic 


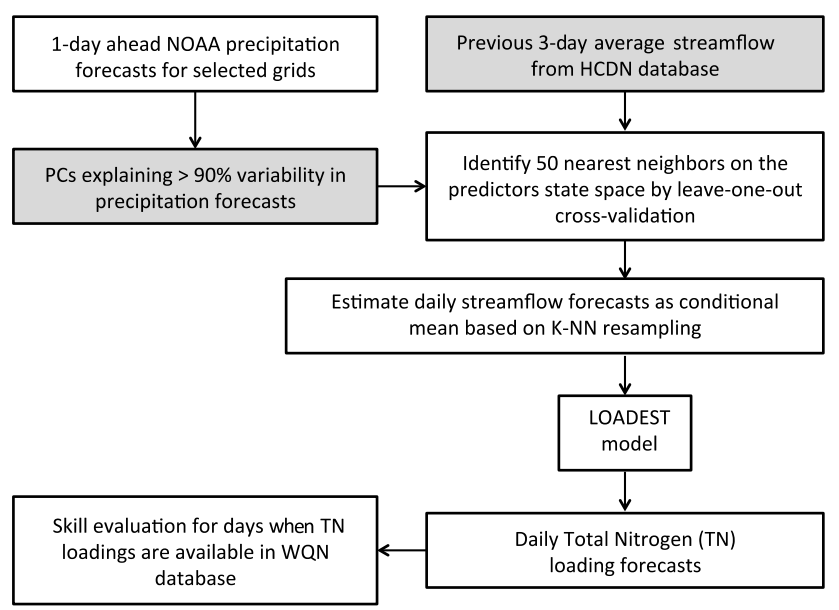

Figure 2. Schematic diagram illustrating the overall approach to forecast daily streamflow and total nitrogen loadings conditioned on the predictors (gray boxes), daily weather forecasts and daily average streamflow values for previous 3 days, based on Kernelnearest neighbor (K-NN) resampling approach.

influences; however, water quality data is influenced by the land use type. Based on the USGS National Land Use Classification Data (NLCD) of 2001, we calculated the percentage area under agricultural and urban (Table 1) land use. From Table 1, we can see the distribution with seven, six and five watersheds having $20-30,10-20$ and $0-10 \%$ of area under agriculture, respectively. On the other hand, the urban land use is less than $10 \%$, with the exception being station \#3 $(23 \%)$. TN loadings for these stations are available over a period of 12-23 years, with samplings being available on average 5 to 6 times per year (Table 1). For additional details regarding the WQN database, see Alexander et al. (1998). We next provide details on the methodologies behind the development of streamflow and total nitrogen loadings forecasts for the selected watersheds.

\section{Streamflow and total nitrogen forecasting models}

The overall schematic diagram of the daily streamflow and nutrients forecasting methodology is shown in Fig. 2. Daily streamflow forecasts using weather forecasts have been pursued by many studies (Day, 1985; Wang et al., 2011; Yang et al., 2014), but efforts to use those streamflow forecasts to develop nutrient forecasts are very limited.

\subsection{Daily streamflow forecasts}

To develop daily streamflow forecasts, we first identified the grid points of large-scale 1-day ahead forecasted precipitation (referred to as FP hereafter) that exhibit significant correlation with daily streamflow from the HCDN database (Table 2). The correlation was considered statistically significant when it was greater than $1.96 / \operatorname{sqrt}(n-3)$, where $n$ denotes the
Table 2. Station ID, number of selected PCs, and cumulative eigenvalues for large-scale precipitation grids from the NOAA's GFS model, which provides 1-day ahead precipitation forecasts (grid numbers are shown in Fig. 1).

\begin{tabular}{clcc}
\hline $\begin{array}{c}\text { Station } \\
\text { ID }\end{array}$ & $\begin{array}{l}\text { Selected grids } \\
\text { (total \# of selected grids) }\end{array}$ & $\begin{array}{c}\text { \# of } \\
\text { selected } \\
\text { PCs }\end{array}$ & $\begin{array}{c}\text { Cumulative eigen- } \\
\text { value of } \\
\text { selected PCs }\end{array}$ \\
\hline 1 & $5,7,12,19-21(6)$ & 4 & 0.962 \\
2 & $5,7,12(3)$ & 2 & 0.905 \\
3 & $4-5,11-13,18-20(8)$ & 4 & 0.948 \\
4 & $11-13,18-20,27(7)$ & 3 & 0.909 \\
5 & $17-18,24-27(6)$ & 3 & 0.922 \\
6 & $9-12,16-19,23-26(12)$ & 4 & 0.903 \\
7 & $24-26,31-33(6)$ & 3 & 0.918 \\
8 & $17-19,24-26,31-33(9)$ & 4 & 0.918 \\
9 & $17-19,24-26,31-33(9)$ & 4 & 0.918 \\
10 & $16-19,23-26,30-33(12)$ & 5 & 0.921 \\
11 & $16-18,23-25,30-32(9)$ & 4 & 0.930 \\
12 & $16,30-32(4)$ & 3 & 0.975 \\
13 & $23-25,30-32(6)$ & 3 & 0.934 \\
14 & $18,22-25,30-32(8)$ & 4 & 0.938 \\
15 & $18,22,24(3)$ & 2 & 0.912 \\
16 & $22,29-31(4)$ & 3 & 0.977 \\
17 & $15-17,22-24,29-31(9)$ & 4 & 0.929 \\
18 & $17,22-24,30-31(6)$ & 3 & 0.932 \\
\hline
\end{tabular}

number of days over the 1979 to 2009 period. This helps us to identify the neighboring grid points that modulate the streamflow of a particular watershed.

Given that the selected large-scale FP grids are intercorrelated with each other, the principal component analysis (PCA) was applied to select the first few principal components which explained over $90 \%$ variability in the precipitation data. PCA, also known as empirical orthogonal function (EOF) analysis, transforms the correlated variables to orthogonal uncorrelated principal components (See details in Oh and Sankarasubramanian, 2013). The number of principal components varies from 2 to 5 among different sites (Table 2). These principal components (PCs) of 1-day ahead FP, as well as daily streamflow over the 3 days prior to the forecasting date, were selected as the predictor for the semiparametric statistical model. For example, to forecast streamflow on a particular day, WQN data was observed on a given day, e.g., 14 March in a given year, and predictors were then the 1-day ahead FP issued on 13 March and the 1-day average daily streamflow from 11 to 13 March in that year. Thus, the number of predictors varies from 3 to 6 (i.e., the number of selected PCs shown in Table 2 and one predictor for the 1-day average streamflow). The streamflow over the previous 3 days could be considered as a surrogate for antecedent soil moisture conditions. Then, the nearest neighbor resampling method was employed to predict daily streamflow for that particular day in which WQN was observed. 


\subsection{K-nearest neighbor (K-NN) resampling approach}

After obtaining the predictors, PCs of the FP grids and 1day average streamflow, we utilized the K-nearest neighbor (K-NN) resampling method proposed by Lall and Sharma (1996). A similar application of the K-NN resampling approach was employed for developing monthly streamflow forecasts conditional on climatic predictors (Souza et al., 2003; Devineni et al., 2008). The K-NN approach resamples daily (or monthly data) from historical data to generate values that were observed in the past. Typically, the $\mathrm{K}$ nearest neighbors are identified between predicted time series and the historical series based on the Euclidean distance. Then a weighing function (e.g., Lall and Sharma, 1996) is generally assigned such that more weights are given to the nearest neighbors, while less weights are given to the farthest neighbors to estimate the predicted time series. Finally, multiple ensembles are generated to estimate the conditional mean of the time series.

In the K-NN scheme, we used the Mahalanobis distance instead of the Euclidean distance, since the selected predictors - PCs of the principal components and the streamflow over the past observations - could be correlated. Therefore, for forecasting the streamflow for a given day observed in the WQN data, all the neighbors were chosen based on the historical time series of 1-day ahead FP and previous 1-day average streamflow for that day over the period 1979 to 2009, leaving out the daily predictors and predictands over the entire forecasting year (i.e., 365 days). This implies that in order to forecast streamflow for a given day, 30 historical years are available (excluding the forecast year) for identifying similar conditions. Since this is a small sample size for identifying neighbors, we also considered daily streamflow over the 3 previous days, resulting in a total 120 neighbors, to develop streamflow forecasts for a given day. The Mahalanobis distance for all 120 neighbors were estimated using Eq. (1) (Mahalanobis, 1936):

$D_{i, j}=\sqrt{\left(\boldsymbol{X}_{i}-\boldsymbol{X}_{j}\right)^{T} S^{-1}\left(\boldsymbol{X}_{i}-\boldsymbol{X}_{j}\right)}$,

where $\boldsymbol{X}_{i}$ and $\boldsymbol{X}_{j}=\left(X_{1}, X_{2}, \ldots, X_{120}\right)$ are the multivariate vectors containing predictor variables at the conditioning time step, $i$ and $j$ denote the rest of the time periods that are considered for identifying the neighbors, with $T$ representing the transpose operation and $S^{-1}$ denoting the inverse of the predictor $\left(X_{j}\right)$ covariance matrix. The matrix, $\mathbf{X} .=\left[x_{1} \cdot x_{2}\right.$. $]$ denotes the multivariate vector, with $x_{1}$. and $x_{2}$. denoting the 1-day averaged streamflow before the forecasted day and the PCs of 1-day ahead FP. The first 50 nearest neighbors and their corresponding daily streamflow values were selected based on Mahalanobis distance, $D_{i, j}$, to develop an ensemble of daily streamflow forecasts. These daily streamflow values from the 50 neighbors were used to draw 500 ensembles that represent the conditional distribution with the density/weight represented by each member, $j$, by the kernel in Eq. (2):

$w_{j}=\frac{1 / j}{\sum_{k=1}^{K} 1 / k}, i=1,2, \cdots, K$,

where $K=50$ (the number of neighbors), and $w_{i}$ represents the probability with which neighbor is resampled in constituting the 500-member ensemble. Finally, the forecasted streamflow for each day is calculated as the conditional mean of these 500 realizations obtained from the 50 neighbors. The ensemble mean of daily streamflow forecasts are specifically obtained for the days on which WQN data is available, so that the ensemble mean of daily streamflow forecasts could be used for developing forecasts of total nitrogen loadings, whose details are described in the next section.

\subsection{Daily nitrogen loadings and concentration forecasts development}

Daily nitrogen loadings forecasts are developed by forcing the daily streamflow forecasts with the Load Estimation (LOADEST) program. The LOADEST model can be employed with the observed or predicted daily streamflow time series at any given site. Streamflow forecast developed using large-scale precipitation forecasts and previous 3-day average streamflow using the non-parametric model is forced with the LOADEST model to develop nutrient forecasts. LOADEST is a statistical model that estimates daily loadings based on the observed daily streamflow and the centered time (dtime) of the year of the observation (Runkel et al., 2004).

$$
\begin{aligned}
\ln \left(L_{j}\right) & =a 0+a 1 \ln \left(Q_{j}\right)+a 2 \ln Q_{j}^{2}+a 3 \sin (2 \pi \mathrm{dtime}) \\
& +a 4 \cos (2 \pi \mathrm{dtime})+\hat{\varepsilon}_{j} \ldots,
\end{aligned}
$$

where $L_{j}$ denotes the observed daily loadings from the WQN database with " $j$ " denoting the day of observation, $Q_{j}$ is the observed daily flow and dtime is the centered time which is a function of the observation's number of days (from 1 January) in the calendar year, $a 0-a 4$ denote the model coefficients and $\hat{\varepsilon}_{j}$ is the estimated residual for the model. The expression dtime is centered to avoid multi-collinearity and dtime also represents the seasonality in loadings pattern. For a detailed expression on dtime, see Cohn et al. (1992).

The LOADEST model allows the user to select the best fitting regression model from 11 predefined regression models using the Akaike information criterion (AIC) (Akaike, 1981). Five regression models that include a linear time trend are not appropriate, since we are employing observed streamflow to estimate simulated loadings for HCDN watersheds. Therefore, the simulated nutrient loadings based on the remaining regression models (i.e., model forms 1, 2, 4 and 6 as defined in Runkel et al., 2004) in the LOADEST program do not have any time trend. Equation (3) represents the model form 6. Model form 1 (2) considers only the first two (three) terms in the right-hand side (RHS) of Eq. (3), whereas model form 
3 considers all the terms except the third term in the RHS of Eq. (3). For further details on model forms, see Runkel et al. (2004). Table 3 shows the goodness of fit statistics (coefficient of determination $\left(R^{2}\right)$ and AIC) in predicting the observed daily loadings in the WQN database (Table 1) and the coefficients of the best fitting regression model for total nitrogen for the selected 18 stations.

From Table 3, we infer that $R^{2}$ ranges from 0.83 to 0.97 , indicating good fit of the observed daily loadings over 18 stations. Using these parameters, we next estimate the forecasts of daily loadings using the ensemble mean of daily streamflow forecasts developed using the retrospective weather forecasts. Strictly speaking, these parameters should have been obtained by leaving out the observed WQN loadings on the day of the forecasting. Since we have more than $50 \mathrm{ob}-$ servations at each site (Table 1), the regression coefficients and model forms did not change substantially. Hence, we used the parameters of the regression coefficients given in Table 3 to estimate the forecasted total nitrogen loadings. These forecasted loadings are divided by the forecasted streamflow to estimate the forecasts of total nitrogen concentrations for the 18 selected watersheds. The forecasted daily streamflow and total nitrogen loadings and concentration are respectively compared with the observed streamflow and the observed WQN daily loadings based on the Spearman rank correlation and root mean square error (RMSE) in predicting the observed information.

\section{Results and analysis}

In this section, we present skill in predicting variability (rank correlation) and accuracy (RMSE) of observed streamflow and WQN loadings using the forecasted daily streamflow obtained using the K-NN approach.

\subsection{Skill in forecasting daily streamflow}

We first summarize the performance of the daily streamflow forecasts for only those days when TN loadings are measured (Fig. 4a). Based on that, we infer that all the stations show statistically significant correlations, with 8 sites showing correlations greater than 0.8 (Fig. 3a). Similarly, RMSE (in cfs per unit area) is less than 1 for all states except stations \#11, 17 and 18 (Fig. 3b). These errors primarily occur due to the inability of the model to predict high values as indicated by very high residuals. For instance, RMSE for station \#17 drops from 3.56 to 0.55 by excluding only one extreme observation recorded on 2 October 1981 (not shown here). The RMSE for station \#11 (\#18) are adjusted to 0.73 (0.29) by dropping one (two) high flow value(s). Although this conditional bias is not observed at all the stations, we infer that the daily streamflow forecast model has poor skill in predicting high flow values. We defer this issue for further discussion at the end of this section. Given this evaluation in predicting ob-
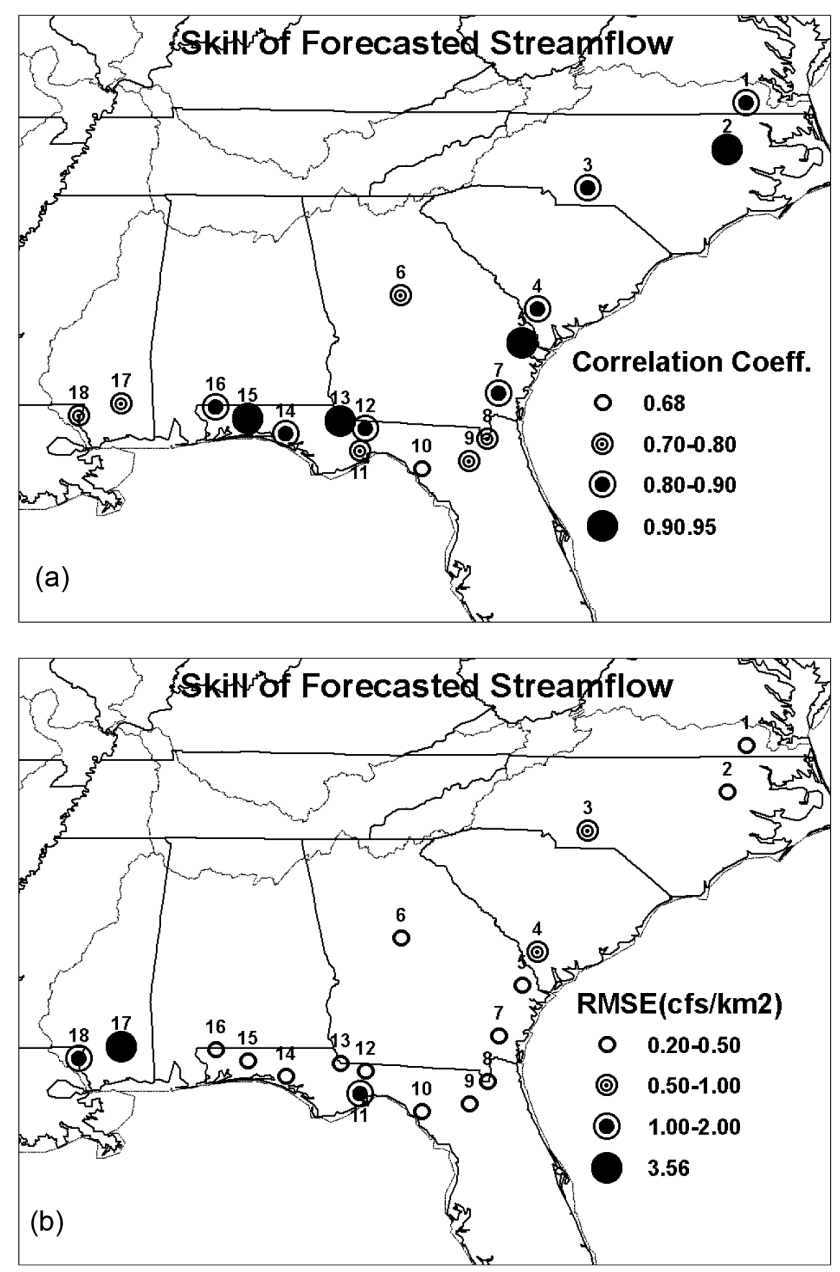

Figure 3. (a) Rank correlation and (b) RMSE (cfs per unit area) between observed daily streamflow and forecasted daily streamflow for those days with TN loadings being available in the WQN database.

served streamflow on days with WQN data, we next evaluate the performance of daily nitrogen loadings and concentration forecasts for the 18 stations.

\subsection{Skill in forecasting total nitrogen loadings and concentration}

Using the ensemble mean of the daily forecasted streamflows as a predictor in the LOADEST model, we estimate the forecasted TN loadings for those days in which measurements are available in the WQN database. Figure $4 \mathrm{a}$ (b) shows rank correlation (RMSE) between forecasted daily loadings and observed loadings for the 18 stations. Daily loadings of $\mathrm{TN}$ forecasts exhibit statistically significant relationships between observation and forecasts at all the stations, with correlation coefficients being greater than 0.8 in nine stations. We also infer that the correlation is higher in coastal regions as opposed to the inland watersheds. Similar to the skill of 
Table 3. Performance of LOADEST model in predicting the observed TN loadings from the WQN database. Models with linear time components (Model no.: 3,5, 7-9) are not considered.

\begin{tabular}{crrrrrrrrr}
\hline \multirow{2}{*}{$\begin{array}{c}\text { Station } \\
\text { index }\end{array}$} & \multirow{2}{*}{$R^{2}$} & \multirow{2}{*}{$\begin{array}{c}\text { AIC } \\
\text { (daily) }\end{array}$} & Model & \multicolumn{6}{c}{ Coefficients of selected LOADEST model } \\
\cline { 6 - 9 } & & & no. & $\mathrm{a} 0$ & $\mathrm{a} 1$ & $\mathrm{a} 2$ & $\mathrm{a} 3$ & $\mathrm{a} 4$ \\
\hline 1 & 0.948 & 0.892 & 4 & 6.768 & 1.114 & -0.283 & -0.069 & \\
2 & 0.966 & -0.131 & 4 & 8.122 & 0.980 & 0.108 & -0.018 & \\
3 & 0.966 & 0.496 & 4 & 8.863 & 1.066 & -0.195 & 0.090 & \\
4 & 0.956 & 0.905 & 6 & 4.446 & 1.013 & 0.026 & 0.238 & -0.036 \\
5 & 0.916 & 0.837 & 4 & 7.721 & 1.069 & -0.084 & -0.317 & \\
6 & 0.853 & 2.094 & 1 & 2.647 & 1.095 & & & \\
7 & 0.968 & 0.518 & 6 & 7.521 & 1.005 & -0.025 & -0.083 & 0.103 \\
8 & 0.963 & 0.250 & 6 & 6.428 & 1.088 & -0.075 & -0.027 & 0.187 \\
9 & 0.986 & -0.219 & 6 & 5.690 & 1.086 & -0.037 & -0.078 & 0.059 \\
10 & 0.979 & 0.279 & 6 & 5.549 & 1.241 & -0.069 & -0.096 & 0.071 \\
11 & 0.979 & 0.516 & 6 & 4.351 & 1.139 & -0.043 & 0.187 & 0.007 \\
12 & 0.923 & 0.585 & 1 & 7.341 & 0.846 & & & \\
13 & 0.902 & 0.193 & 4 & 10.563 & 0.981 & 0.074 & 0.165 & \\
14 & 0.835 & 0.423 & 4 & 9.077 & 0.931 & -0.145 & -0.042 & \\
15 & 0.834 & 1.085 & 6 & 7.238 & 1.123 & -0.131 & -0.004 & 0.176 \\
16 & 0.873 & 0.758 & 4 & 8.868 & 1.039 & 0.147 & 0.032 & \\
17 & 0.912 & 1.233 & 4 & 4.555 & 1.188 & 0.206 & 0.328 & \\
18 & 0.899 & 0.853 & 1 & 10.193 & 1.047 & & & \\
\hline
\end{tabular}

daily streamflow forecasts, loadings forecasts produce high RMSE in some stations, despite their ability to predict the observed variability. This failure in forecasting TN loadings is primarily due to the inability to estimate high flow events as discussed in Sect. 4.1.

Further extending our analysis, we estimated TN concentration from the LOADEST model utilizing the forecasted streamflow and loadings and then compared the forecasted TN concentration with the observed concentrations available in the WQN database (Fig. 5). Though the forecasted concentration is smaller compared to the correlation reported for streamflow and loadings, the correlation is statistically significant at all stations except stations \#6 and \#18. Given that concentration is the ratio of loadings to the streamflow, the error in predicting both loadings and streamflow result in reduced skill. We are not reporting the RMSE since the trend is similar to Figs. 4 and 5.

\subsection{Factors affecting the skill in forecasting $\mathrm{TN}$ loadings}

In order to understand what factors control the skill in forecasting the TN loadings utilizing the weather forecasts, we plotted the rank correlation against basin area (Fig. 6). Rank correlation in forecasting streamflow (Fig. 6a) and TN loadings (Fig. 6b) are statistically significant for all the stations and the skill increases as the drainage area increases, which is consistent with previous findings (Bloeschl and Sivapalan, 2013). This is primarily due to the fact that retrospective weather forecasts being available over large spatial scales, the developed streamflow and TN loadings forecasts modulate better with the observed streamflow and WQN loadings.

To gain further understanding on how the developed model estimates the observed streamflow and nutrients, we present the performance of daily streamflow and $\mathrm{TN}$ forecasts for the sites that have the best and worst skill under each case (Fig. 7). For quantifying the performance of streamflow, we considered the continuous daily streamflow records available from USGS instead of comparing the performance on the days with WQN data. From streamflow forecasts for the site with best skill (Fig. 7a), we understand that overall performance is good, but the K-NN resampling approach based on daily streamflow forecasts consistently underestimates high flow events. This underestimation/error in streamflow forecasts partially arises from the errors in the precipitation forecasts also. We discuss this issue in detail in the next section. From Fig. 7b, the site performs poorly in forecasting flows above $8000 \mathrm{cfs}$. It is important to note that for the same site we observed significant correlation in predicting both the streamflow and the loadings on those days with WQN data being present. Thus, evaluating the performance of the $\mathrm{K}-\mathrm{NN}$ resampling model over the entire time series of observed records provides a more confirmatory evaluation of the model. The primary reason the K-NN resampling model performs poorly at site 3 (Rocky River near Norwood, NC) is due to the limited correlation between the observed precipitation and the forecasted precipitation during the summer months (figure not shown). Thus, the error resulting from $\mathrm{K}$ $\mathrm{NN}$ resampling arises from both errors in the precipitation forecasts and in estimating the initial conditions as well as 

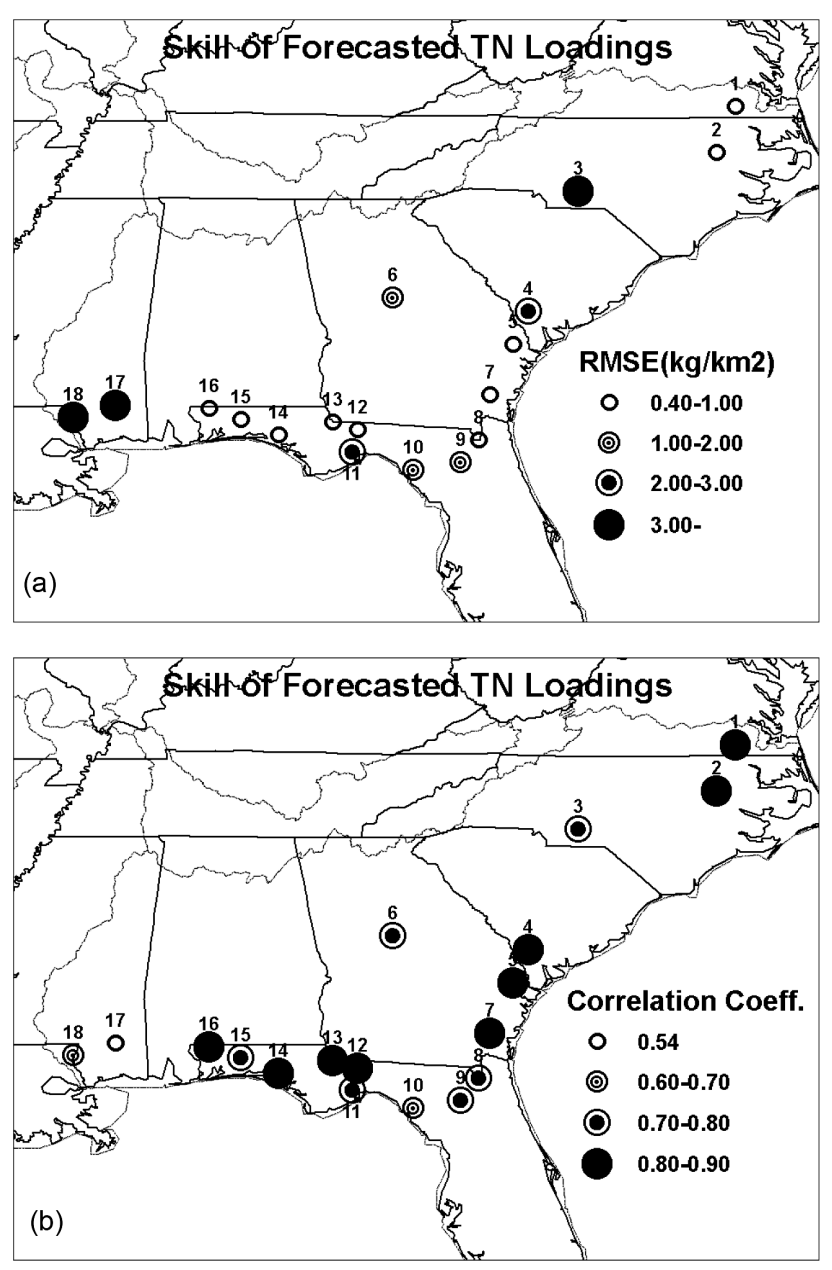

Figure 4. (a) Rank correlation and (b) RMSE between observed TN loadings and forecasted TN loadings for those days with TN loadings being available in the WQN database.

from the model itself. Even if one uses physically based distributed models (e.g., Sacramento model), the skill of streamflow forecasts is heavily dependent on the skill of precipitation forecasts as well as the season of forecasting.

Figure $7 \mathrm{c}$ shows the performance of the TN loading forecasts obtained using the streamflow forecasts with the LOADEST model. Even here, the same issue is highlighted with the limited ability of the forecasts in predicting the nutrients on days with high flows, resulting in underestimated TN loadings. But the model estimates the variability of the observed nutrients very well. Figure $7 \mathrm{~d}$ shows the performance of TN loadings for a station with the worst skill. The skill of the streamflow forecasts resulting from the K-NN resampling approach in predicting the observed daily streamflow recorded at USGS stations is marginal with an average daily correlation of 0.6. Given that the $R^{2}$ of the LOADEST model is 0.912 for the selected station (Table 3 ), the poor performance primarily results from the inability of the streamflow forecasts, which partly arises from the resampling model as

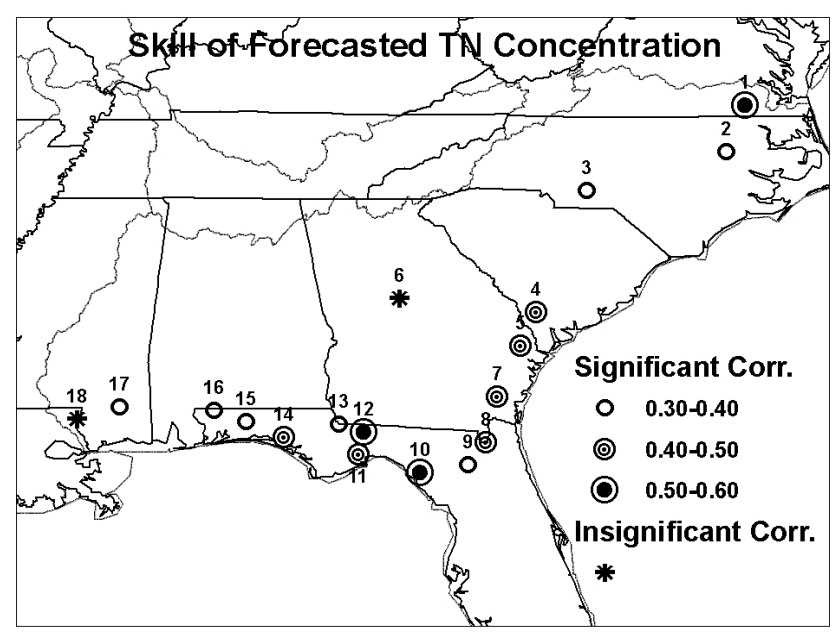

Figure 5. Correlation between observed TN concentration and forecasted TN concentration for those days with TN loadings being available in the WQN database.
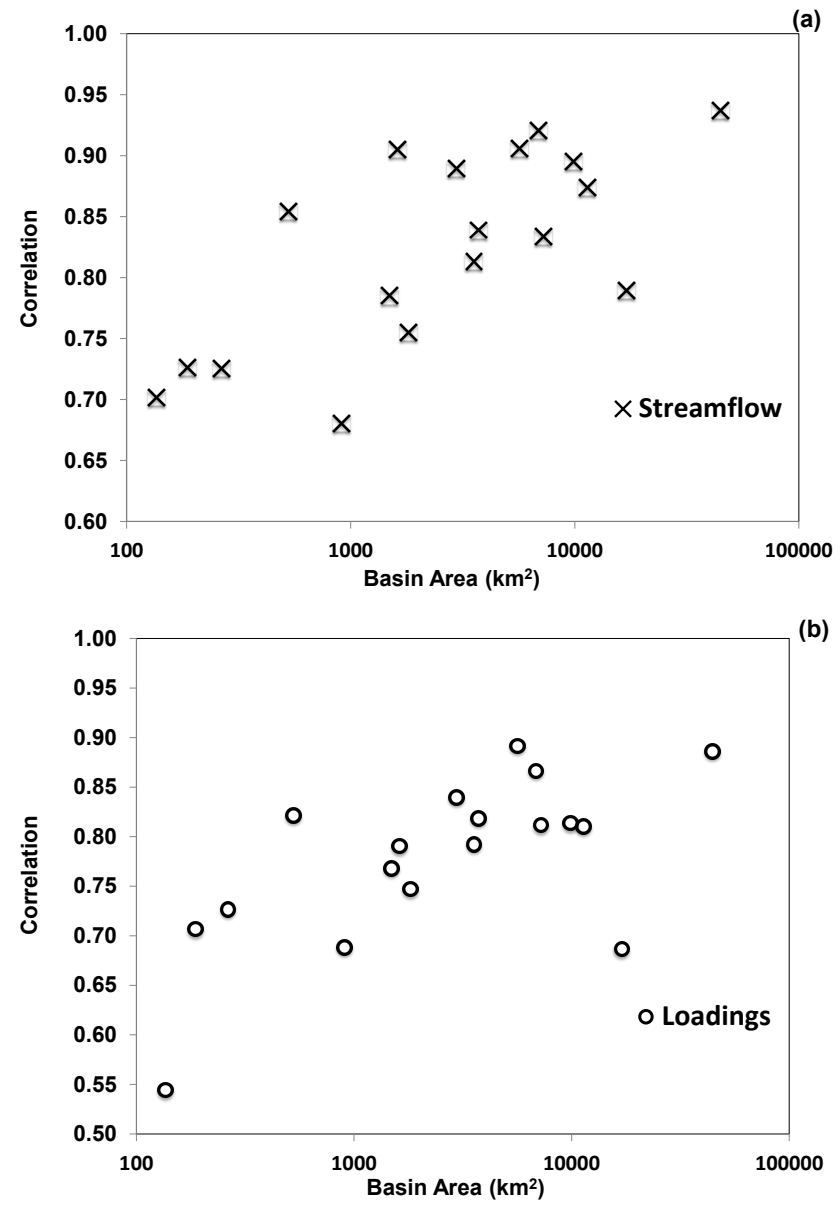

Figure 6. Role of basin scale and drainage area in forecasting observed (a) streamflow and (b) TN loadings provided in the WQN database for the 18 stations. 

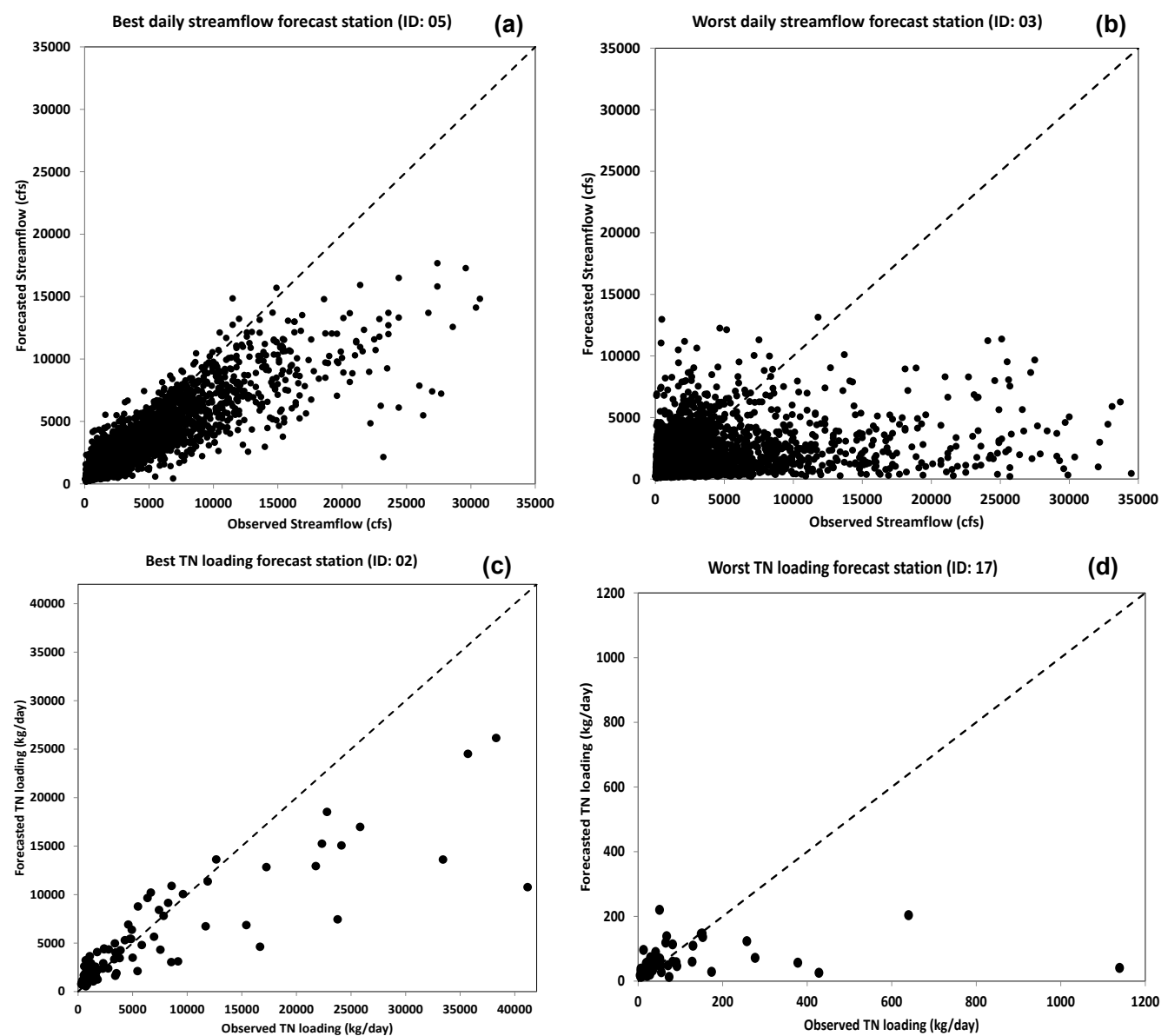

Figure 7. Comparison of observations and forecasts of streamflow (a and $\mathbf{b})$ and TN loadings (c and d) for the stations with best (Streamflow: Ogeechee River near Eden, GA, TN: Tar River at Tarboro, NC) and worst forecasting skill (Streamflow: Rocky River near Norwood, NC, TN: Cypress Creek near Janice, MS).

well as from the skill of the precipitation forecasts. Thus, to develop nutrient forecasts, it is important that the skill of daily precipitation and streamflow forecasts should be good and also the load estimation model should have very high skill in predicting the observed nutrients. Given that these basins are virgin, it could be argued the predominant source of nutrient loadings arise from the non-point sources whose primary transport is the streamflow. Thus, to develop a broader understanding of what could be achieved in forecasting daily nutrients in virgin basins, one could look at the skill in predicting daily streamflow forecasts using the retrospective weather forecasts for the selected 18 stations. We summarize this information under the discussion in the next section by summarizing the skill of daily streamflow forecasts under each month for the selected 18 stations.

\subsection{Discussion}

The intent of this study is to develop daily forecasts of total nitrogen (TN) loadings and its concentration in 18 HCDN watersheds that are minimally impacted by anthropogenic in- fluences over the southeastern US. Given that these watersheds experience virgin flow, our hypothesis is that most of the nutrient transport at daily timescales could be explained based on observed streamflow. For this purpose, we related the observed daily streamflow and loadings using the LOADEST model (Table 3), which showed significant skill in predicting the daily variability in TN loadings purely based on observed streamflow. Given that the predominant driver of streamflow in watersheds under the rainfall-runoff regime is precipitation, we utilized the retrospective 1-day ahead precipitation forecasts from the reforecasts database of Hamill et al. (2004) and daily streamflow over the previous 3 days (as a surrogate for soil moisture storage) for developing daily streamflow forecasts on the days with recorded WQN observations. The forecasted ensemble average of the streamflow obtained using the K-NN resampling model was used within the LOADEST model to estimate the forecasted daily TN loadings and the concentrations. We observed the correlation between observed TN loadings and the forecasted TN loadings as being significant in almost all the stations. 


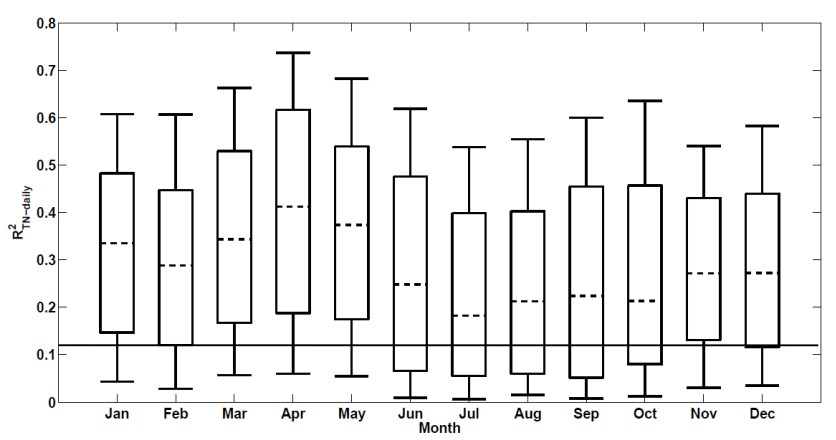

Figure 8. Box plot showing rank correlations between observed daily streamflow and forecasted streamflow aggregated over each month from 1979 to 2009 . Each plot includes 558 correlations (18 stations $\times 31$ years). The solid line represents the statistically significant $(95 \%) R^{2}$ corresponding to the null hypothesis that $R^{2}$ equals zero.

But the forecasted concentration showed reduced skill, since it accounted for the errors in both loadings and streamflow. Though one could improve the streamflow forecasts developed using the K-NN resampling approach by considering physically distributed hydrologic models and by explicitly considering additional input variables (e.g., temperature forecasts, humidity), we certainly captured the first-order information on the daily streamflow variability by utilizing the retrospective precipitation forecasts and employed that for assessing the potential in developing nutrient forecasts. Another advantage with the streamflow forecasts using the $\mathrm{K}-\mathrm{NN}$ approach is in specifying the conditional distribution of flows. Thus, one could use the conditional distribution of streamflows with the LOADEST model to develop the conditional distribution of loadings, which could be used to estimate the probability of violating the concentration at the daily timescale.

It is important to note that all the skill reported in Figs. 36 consider the ability to predict those days when the WQN observations are available. The primary difficulty in assessing the potential for developing nutrient forecasts at daily timescale is the discontinuous nutrient samplings recorded in the WQN database. Oh and Sankarasubramanian (2012) addressed this issue by computing the coefficient of determination $\left(R^{2}\right)$ of the winter TN loading forecasts as a product of the $R^{2}$ in forecasting the seasonal streamflow and the $R^{2}$ of the LOADEST model for the winter season. Similarly, we express the skill of TN forecasts (Eq. 4) at daily timescale as a product of the $R^{2}$ of streamflow $(Q)$ forecasts developed from the K-NN approach for each day in the calendar year and the $R^{2}$ of the LOADEST model reported in Table 3.

$R_{\mathrm{TN} \text {-daily }}^{2}=R_{(\mathrm{LOADEST})}^{2} * R_{Q \text {-daily }}^{2} \cdots$

$R_{Q \text {-daily }}^{2}$ is computed between the observed daily streamflow over the period 1979-2010 and the computed ensemble mean of the streamflow forecast from the K-NN resampling ap- proach. Since the skill of daily streamflow forecasts differ substantially depending on the season, we plot the $R_{\mathrm{TN} \text {-daily }}^{2}$ as a box plot for each month (Fig. 8). Basically, Fig. 8 pools the daily correlation, $R_{\mathrm{TN} \text {-daily }}^{2}$, for a given month across the 18 stations. For instance, in January, we expect $31 \times 18$ daily correlations and the box plot simply summarizes the skill in predicting daily $\mathrm{TN}$ for that month over the southeast US. About $75 \%$ of the $R_{\mathrm{TN} \text {-daily }}^{2}$ at daily level are at a statistically significant level over the period January to May and also from November to December (Fig. 8). Daily TN forecasts show relatively better skills in predicting observed TN variability during the winter and spring. On the other hand, the skill of $R_{\mathrm{TN} \text {-daily }}^{2}$ is poor during the summer and fall seasons. It is well known that retrospective precipitation forecasts have lower skill during the warm season (Hamill et al., 2004). One of the possible reasons of relatively poor skill during summer and fall is that weather phenomena during these seasons depend greatly on local-scale processes, while largescale models do not have the ability to capture it (Hamill et al., 2006). Thus, the poor skill of $R_{\mathrm{TN} \text {-daily }}^{2}$ primarily arises from the skill in forecasting precipitation during the summer and fall seasons. Additionally, the role of temperature during the summer season is also much higher with enhanced evapotranspiration. However, considering temperature as an additional predictor did not result in a substantial increase in the $R_{Q \text {-daily }}^{2}$ for the summer season. Perhaps if one considers a physically based hydrologic model, the skill in predicting daily streamflow could improve during the summer season. We plan to investigate this in future work in assessing the potential for developing nutrient forecasts, with streamflow forecasts being derived from a physically based distributed hydrologic model. Thus, the potential skill $\left(R_{\mathrm{TN}-\text { daily }}^{2}\right)$ in predicting daily nutrients is statistically significant for the winter and spring season in almost all the stations. One could utilize this to develop adaptive nutrient management strategies for controlling the point sources (e.g., waste water treatment plants) so that the downstream TN concentration does not exceed the desired/EPA standards.

Given that consideration of both forecasted precipitation and 3-day average streamflow prior to the forecasting day exhibit significant skill in predicting the observed TN loadings from the WQN database, we investigated the role of each predictor in contributing to the overall skill reported in Figs. 3-5. This analysis will also provide information on the role of basin storage, i.e., 3-day average streamflow, in contributing to the forecast skill. For this purpose, we developed the streamflow forecasts using only one predictor and then used that streamflow forecast to estimate the TN loadings. Figure 9 quantifies the role of each predictor, 3day average streamflow prior to forecasting day $(Q)$ and 1day ahead precipitation forecasts (FP), in contributing to the skill, correlation and RMSE, in forecasting TN loadings for all the 18 sites. It is important to note that the correlation and RMSE were obtained by forecasting for the actual day for which the samples are available in a given site in the WQN 

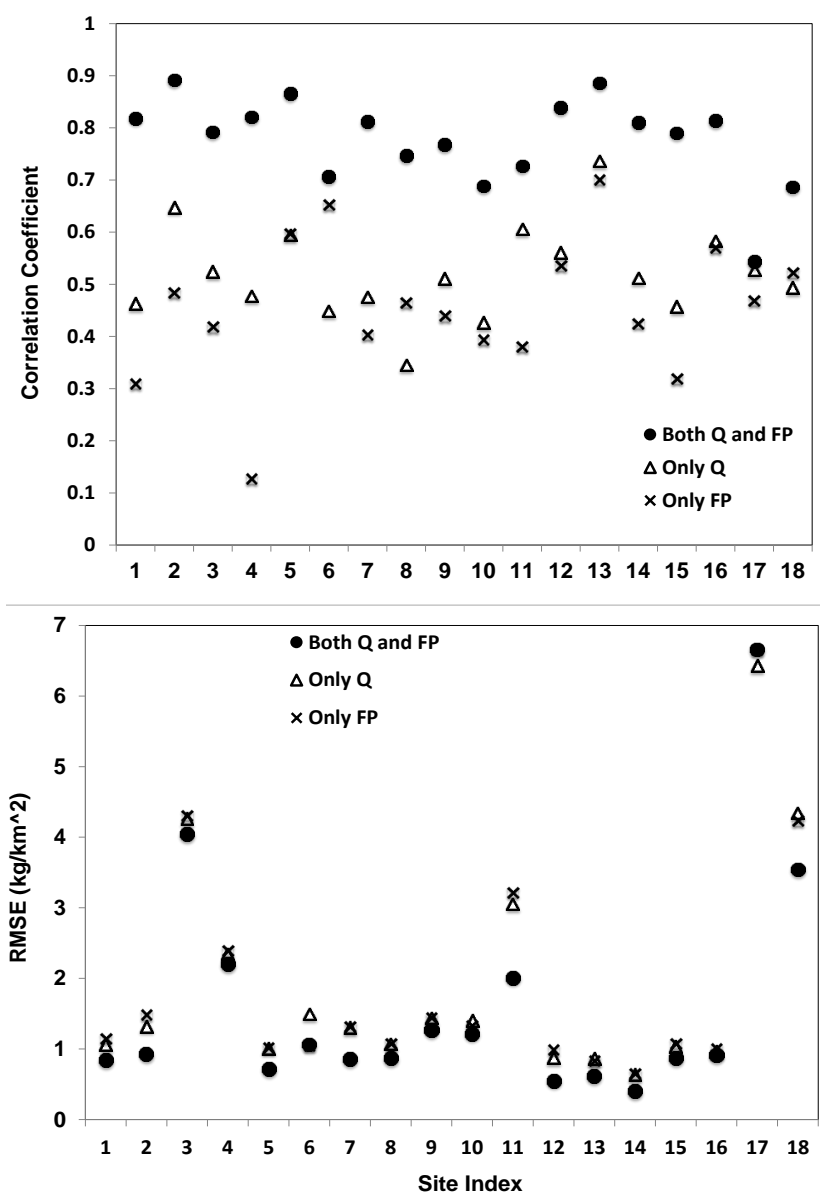

Figure 9. The role of different predictors, 3-day average daily streamflow prior to forecasting day $(Q)$ and 1-day ahead precipitation forecasts (FP), in forecasting the observed TN loadings is expressed as (a) correlation coefficient and (b) RMSE between the observed $\mathrm{TN}$ and the forecasted $\mathrm{TN}$ loadings for the 18 selected sites.

database. Figure 9 clearly indicates that the combination of both 3-day average streamflow and 1-day ahead precipitation forecasts as predictors result in improved correlation and reduced RMSE in estimating daily TN loadings at all the sites. Comparing the skill obtained using only one predictor, 3-day average streamflow or forecasted precipitation, we infer that for most of the watersheds, the skill obtained using 3-day average streamflow (prior to the forecasting day) alone as a predictor provides better skill in comparison to the skill obtained using forecasted precipitation alone as a predictor, with the exception being stations 6,8 and 18. On an average, in most of the basins, 3-day average streamflow prior to the forecasts alone can explain around $25 \%$ (average correlation across all the sites is 0.52 ) of the variability in the observed nutrients. Several studies have shown that antecedent moisture/flow conditions also play a critical role in influencing the nutrient loadings from the watershed (Vecchia, 2003; Alexander and Smith, 2006). This analysis further confirms

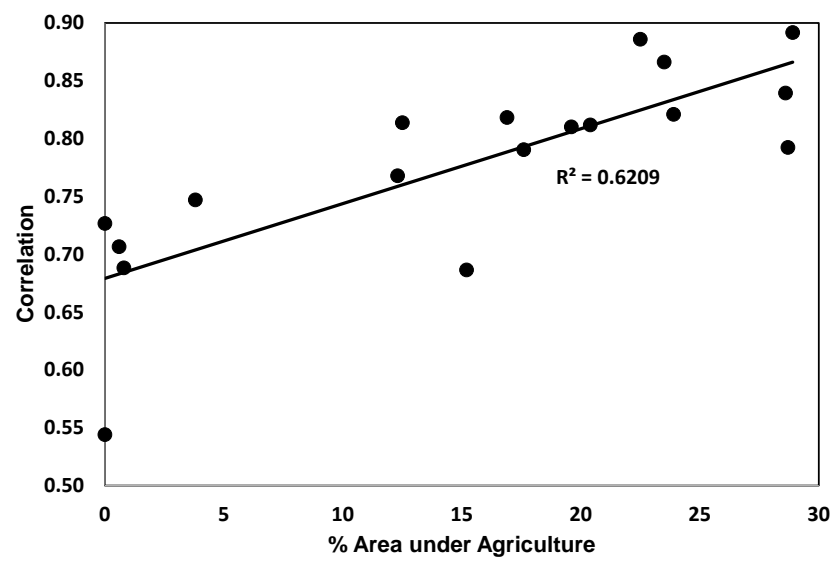

Figure 10. Role of the type of land use and percentage area under agriculture in influencing the forecast skill, which is expressed as the correlation coefficient between the observed TN loadings and the forecasted TN loadings for the 18 selected watersheds.

the critical role of basin storage, both streamflow and nutrients, in influencing the forecast skill. On the other hand, forecasted precipitation alone can explain on average $20 \%$ (average correlation across all the sites is 0.45 ) of the variability in the observed TN loadings in the WQN database. Thus, including both of them as a predictors in the proposed modeling framework results in overall improvement.

We also investigated how the type of land use influences the skill in forecasting TN loadings. Figure 10 shows the scatter plot between the forecast skill, correlation coefficient between the observed $\mathrm{TN}$ loadings and the forecasted TN loadings, and the percentage area under agriculture for each watershed. This indicates basins with higher percentage of agricultural land exhibits higher skill in forecasting the TN loadings. Basins with increased agricultural activity could potentially experience increased fertilization application, which could increase the streamflow-induced transport. This indicates the role of basin nutrient storage in influencing the forecast skill. Similar analyses on urban land use did not reveal any relationship with the skill. Thus, analyses from Figs. 9 and 10 show that both antecedent moisture conditions and in-basin nutrient storage influence the forecast skill for the selected 18 stations over the SEUS.

\section{Summary and conclusions}

We developed a semi-parametric statistical model, which utilizes 1-day ahead precipitation forecasts from the reforecasts from the NOAA GFS climate model (Hamill et al., 2004) and daily streamflow over the previous 3 days as predictors in order to develop daily streamflow forecasts, which in turn was used to implement a load estimation model, LOADEST, for estimating daily nutrients. For each day, conditioned on the previous day's streamflow and 1-day ahead forecasted 
precipitation, 50 nearest neighbors over a 3-day window were selected based on the Mahalanobis distance and then observed daily streamflow corresponding to those 50 neighbors were resampled to constitute 500 ensemble members to develop a daily streamflow forecast. It is important to note that to develop a forecast for a given day in a year, the entire year's predictors and predictand were left out for identifying the 50 nearest neighbors. Finally, the conditional mean of this daily streamflow ensemble was forced in the LOADEST model to obtain daily forecasts of TN loadings and concentration for days with recorded WQN observations. Skill in developing forecasts of streamflow, TN loadings and the associated concentration were computed using rank correlation and RMSE by comparing the respective forecast values with the WQN observations for the selected $18 \mathrm{HCDN}$ stations. The forecasted daily streamflow and TN loadings and their concentration exhibit statistically significant skill in predicting the respective daily observations in the WQN database at all the 18 stations over the SEUS.

The study also found that the skill in predicting the observed TN loadings is higher for large watersheds, indicating the large-scale precipitation forecasts from the reforecast database better correlate with precipitation and streamflow over large watersheds. Analyses also showed that compared to the forecast precipitation, the 3-day average streamflow prior to the forecasting period played a dominant role in contributing to the skill of the forecast. We also observed the skill in forecasting TN loadings is higher for basins having a higher percentage of the area under agriculture. These findings confirm that basin storage, streamflow and nutrients play a critical role in influencing the skill of the forecast. Further, to overcome the limited samplings of TN in the WQN data, we extended the analyses by developing retrospective daily streamflow forecasts over the period 19792012 using reforecasts based on the K-NN resampling approach. Based on the coefficient of determination $\left(R_{Q \text {-daily }}\right)$ of the daily streamflow forecasts, we computed the potential skill $\left(R_{\mathrm{TN} \text {-daily }}^{2}\right)$ in developing daily nutrient forecasts based on the $R^{2}$ of the LOADEST model for each station. The analyses showed that the forecasting skills of TN loadings are relatively better in winter and spring months, while skills are inferior during summer months. These findings are consistent with other studies (Devineni and Sankarasubramanian, 2010; Sinha and Sankarasubramanan, 2013) which show that largescale precipitation forecasts derive their skill from ENSO climatic modes in the SEUS. One possible reason for this poor skill in summer is due to the dominance of local-scale processes during the summer season. Other possible reasons could be due to the limitations in the methodology. We resampled neighbors to develop daily streamflow ensemble, which of course will not have members beyond the maximum observation over the selected 50 neighbors. Further, air temperature can play a dominant role during the summer and fall seasons, resulting in enhanced evapotranspira- tion and reduced baseflow from the watershed. Despite these limitations, there is potential in utilizing the daily streamflow forecasts for developing daily nutrient forecasts, which could be employed for various adaptive nutrient management strategies for ensuring better water quality.

Though the watersheds considered under this study have experienced moderate agricultural activity, extending the above modeling framework for basins experiencing significant urbanization will require additional information. For instance, as the basin gets urbanized, it is natural to expect the point TN loadings from waste water treatment (WWT) plants to influence the downstream loadings and concentration. Under such situations, it would be useful to consider the discharges from the WWT plants as predictors in developing the model. One could also use the TN forecast to control point loadings so that the downstream TN concentration is within the prescribed standard.

For basins experiencing significant non-point pollution from agriculture, one could use information from remote sensing satellites that quantify the chlorophyll concentration could be also be considered as nutrient storage in the river reach and water bodies (Jones et al., 2005). Thus, adequate monitoring of changes in basin land use and nutrient conditions could provide additional information in developing a TN forecasting model for watersheds experiencing significant human interference.

Acknowledgements. The first author's $\mathrm{PhD}$ dissertation research was partially supported by the US National Science Foundation CAREER grant CBET-0954405. Any opinions, findings, and conclusions or recommendations expressed in this paper are those of the authors and do not reflect the views of the NSF. Authors also wish to thank Rob Runkel of USGS for his support in setting up the LOADEST model.

Edited by: F. Tian

\section{References}

Akaike, H.: Likelihood of a model and information criteria, J. Econometrics, 16, 3-14, 1981.

Alexander, R. B. and Smith, R. A.: Trends in the nutrient enrichment of U.S. rivers during the late 20th century and their relation to changes in probable stream trophic conditions, Limnol. Oceanogr., 51, 639-654, 2006.

Alexander, R. B., Slack, J. R., Ludtke, A. S., Fitzgerald, K. K., and Schertz, T. L.: Data from selected US Geological Survey national stream water quality monitoring networks, Water Resour. Res., 34, 2401-2405, 1998.

Alexander, R. B., Smith, R. A., and Schwarz, G. E.: Effect of stream channel size on the delivery of nitrogen to the Gulf of Mexico, Nature, 403, 758-761, 2000.

Anderson, M. L., Chen, Z.-Q., Kavva, M. L., and Feldman, A.: Coupling HEC-HMS with atmospheric models for prediction of watershed Runoff, J. Hydrol. Eng., 7, 312-318, 2002. 
Bloeschl, G., M. Sivapalan, Wagener, T., Viglione, A., and Savenije, H.: Runoff prediction in ungauged basins: synthesis across processes, places and scales, Cambridge University Press, 2013.

Borsuk, M. E., Stow, C. A., and Reckhow, K. H.: Confounding effect of flow on estuarine response to nitrogen loading, J. Environ. Eng., 130, 605-614, 2004.

Bricker, S. B., Clement, C. G., Pirhalla, D. E., Orlando, S. P., and Farrow, D. R. G.: National Estuarine Eutrophication Assessment. Effects of Nutrient Enrichment in the Nation's Estuaries, NOAA - NOS Special Projects Office, 1999.

Caraco, N. F. and Cole, J. J.: Regional-scale export of C, N, P and sediment: what river data tell us about key controlling variables, in: Integrating Hydrology Ecosystem Dynamics and Biogeochemistry in Complex Landscapes, edited by: Tenhunen, J. D. and Kabat, P., John Wiley, New York, 239-253, 1999.

Chiew, F. H. S. and McMahon, T. A.: Global ENSOstreamflow teleconnection, streamflow forecasting and interannual variability, Hydrol. Sci. J., 47, 505-522, 2002.

Cigizoglu, H. K.: Estimation, forecasting and extrapolation of river flows by artificial neural networks, Hydrol. Sci. J., 48.3, 349361, 2003.

Clark, M. P. and Hay, L. E.: Use of medium-range numerical weather prediction model output to produce forecasts of streamflow, J. Hydrometeorol., 5, 15-32, 2004.

Cohn, T. A., Caulder, D. L., Gilroy, E. J., Zynjuk, L. D., and Summers, R. M.: The validity of a simple statistical model for estimating fluvial constituent loads: An Empirical study involving nutrient loads entering Chesapeake Bay, Water Resour. Res., 28, 2353-2363, 1992.

Day, G.: Extended Streamflow Forecasting Using NWSRFS, J. Water Resour. Plann. Manage., 111, 157-170, 1985.

Devineni, N. and Sankarasubramanian, A.: Improved categorical winter precipitation forecasts through multimodel combinations of coupled GCMs, Geophys. Res. Lett., 37, L24704, doi:10.1029/2010GL044989, 2010.

Devineni, N., Sankarasubramanian, A., and Ghosh, S.: Multi-model Ensembling of Probabilistic Streamflow Forecasts: Role of Predictor State Space in skill evaluation, Water Resour. Res., 44, W09404, doi:10.1029/2006WR005855, 2008.

Duff, J. H., Tesoriero, A. J., Richardson, W. B., Strauss, E. A., and Munn, M. D.: Whole stream response to nitrate loading in three streams draining agricultural landscapes, J. Environ. Qual., 37, 1133-1144, 2008.

Galloway, J. N., Schlesinger, W. H., Levy I. H., Michaels, A., and Schnoor, J. L.: Nitrogen fixation: Anthropogenic enhancementenvironmental response, Global Biogeochem. Cy., 9, 235-252, 1995.

Georgakakos, A. P., Yao, H., and Georgakakos, K. P.: Upstream regulation adjustments to ensemble streamflow predictions, HRC Technical Report 7, Hydrologic Research Center, San Diego, CA, 30 June, 2010 (NA08NWS4620023), 63 pp., 2010.

Goolsby, D. A. and Battaglin, W. A.: Long-term changes in concentrations and flux of nitrogen in the Mississippi River basin, USA, Hydrol. Process., 15, 1209-1226, 2001.

Hamill, T. M., Whitaker, J. S., and Wei, X.: Ensemble reforecasting: Improving medium-range forecast skill using retrospective forecasts, Mon. Weather Rev., 132, 1434-1447, 2004.
Hamill, T. M., Whitaker, J. S., and Mullen, S. L.: Reforecasts, an important dataset for improving weather predictions, B. Am. Meteorol. Soc., 87, 33-46, 2006.

Howarth, R. W., Billen, G., Swaney, D., Townsend, A., Jaworski, N., Lajtha, K., Downing, A., Elmgreen, R., Caraco, N., Jordan, T., Berendse, F., Freney, J., Kudeyarov, V., Murdoch, P., and Zhao-liang, Z.: Regional nitrogen budgets and riverine N \& $\mathrm{P}$ fluxes for the drainages to the North Atlantic Ocean: Natural and human influences, Biogeochemistry, 35, 181-226, 1996.

Jones, M. O., Kimball, J., Running, S. W., Ellis, B. K., and Klene, A. E.: Application of MODIS for monitoring water quality of a large oligotrophic lake, Eos Trans. AGU, 85, B41A-0160, 2005.

Kalnay, E., Kanamitsu, M., Kistler, R., Collins, W., Deaven, D., Gandin, L., Iredell, M., Saha, S., White, G., Woollen, J., Zhu, Y., Chelliah, M., Ebisuzaki, W., Higgins, W., Janowiak, J., Mo, K. C., Ropelewski, C., Wang, J., Leetmaa, A., Reynolds, R., Jenne, R., and Joseph, D.: The NCEP/NCAR 40-Year Reanalysis Project, B. Am. Meteorol. Soc., 77, 437-472, 1996.

Lall, U. and Sharma, A.: A nearest neighbor bootstrap for resampling hydrologic time series, Water Resour. Res., 32, 679-693, 1996.

Lin, J., Xie, L., Pietrafesa, L. J., Ramus, J. S., and Paerl, H. W.: Water quality gradients across Albemarle-Pamlico estuarine system: Seasonal variations and model applications, J. Coastal Res., 23, 213-229, 2007.

Mahalanobis, P. C.: On the generalised distance in statistics. Proc. National Institute of Sciences of India 2, 49-55, 1936.

Mcenery, J., Ingram, J., Duan, Q., Adams, T., and Anderson, L.: NOAA'S Advanced Hydrologic Prediction Service: Building Pathways for Better Science in Water Forecasting, B. Am. Meteorol. Soc., 86, 375-385, 2005.

Mujumdar, P. P. and Kumar, D. N.: Stochastic models of streamflow: some case studies, Hydrol. Sci. J., 35, 395-410, 1990.

North Carolina DENR Fiscal analysis for proposed nutrient strategy for Falls of Neuse Reservoir report, available at: http://portal.ncdenr.org/c/document_library/get_file?uuid= 2a29f5a4-3db1-4c63-bd63-cad51a5ac385\\& groupId=38364 (last access: 29 July 2014), 2010.

Oh, J. and Sankarasubramanian, A.: Interannual hydroclimatic variability and its influence on winter nutrient loadings over the Southeast United States, Hydrol. Earth Syst. Sci., 16, 22852298, doi:10.5194/hess-16-2285-2012, 2012.

Paerl, H. W., Valdes, L. M., Peierls, B. L., Adolf, J. E., and Harding, L. W.: Anthropogenic and climatic influences on the eutrophication of large estuarine ecosystems, Limnol. Oceanogr., 51, 448462, 2006.

Piechota, T. C., Chiew, F. H. S., Dracup, J. A., and McMahon, T. A.: Development of exceedance probability streamflow forecast, J. Hydrol. Eng., 6, 20-28, 2001.

Pinckney, J. L., Paerl, H. W., and Harrington, M. B.: Responses of the phytoplankton community growth rate to nutrient pulses in variable estuarine environments, J. Phycol., 35, 1455-1463, 1999.

Prairie, J., Rajagopalan, B., Fulp, T., and Zagona, E.: Modified KNN model for stochastic streamflow simulation, J. Hydrol. Eng., 11, 371-378, 2006.

Rabalais, N. N., Turner, R. E., and Scavia, D.: Beyond science into policy: Gulf of Mexico hypoxia and the Mississippi River, Bioscience, 52, 129-144, 2002. 
Rajagopalan, B. and Lall, U.: A k-nearest-neighbor simulator for daily precipitation and other weather variables, Water Resour. Res., 35, 3089-3101, 1999.

Runkel, R. L., Crawford, C. G., and Cohn, T. A.: Load Estimator (LOADEST): A FORTRAN Program for Estimating Constituent Loads in Streams and Rivers, US Geological Survey Report, 2004.

Salas, J. and Lee, T.: Nonparametric Simulation of Single-Site Seasonal Streamflows, J. Hydrol. Eng., 15, 284-296, 2010.

Sharif, M. and Burn, D.: Simulating climate change scenarios using an improved K-nearest neighbour model, J. Hydrol., 325, 179196, 2006.

Sinha, T. and Sankarasubramanian, A.: Role of climate forecasts and initial conditions in developing streamflow and soil moisture forecasts in a rainfall-runoff regime, Hydrol. Earth Syst. Sci., 17, 721-733, doi:10.5194/hess-17-721-2013, 2013.

Slack, J. R., Lumb, A., and Landwehr, J. M.: Hydro-Climatic Data Network (HCDN) Streamflow Data Set, 1874-1988, US Geological Survey Report, 1993.

Souza Filho, F. and Lall, U.: Seasonal to interannual ensemble streamflow forecasts for Ceara, Brazil: applications of a multivariate, semi-parametric algorithm, Water Resour. Res., 39, 1307-1325, 2003.
Srinivas, V. V. and Srinivasan, K.: Post-blackening approach for modeling dependent annual streamflows, J. Hydrol., 230, 86$126,2000$.

Turner, R. E. and Rabalais, N. N.: Changes in Mississippi River Water Quality this Century, Bioscience, 41, 140-147, 1991.

Vecchia, A. V.: Relation Between Climate Variability and Stream Water Quality in the Continental United States, Hydrol. Sci. Technol., 19, 77-98, 2003.

Vitousek, P. M., Aber, J. D., Howarth, R. W., Likens, G. E., Matson, P. A., Schindler, D. W., Schlesinger, W. H., and Tilman, G. D.: Human alteration of the global nitrogen cycle: Sources and consequences, Ecol. Appl., 7, 737-750, 1997.

Wang, E., Zhang, Y., Luo, J., Chiew, F. H. S., and Wang, Q. J.: Monthly and seasonal streamflow forecasts using rainfall-runoff modeling and historical weather data, Water Resour. Res., 47, W05516, doi:10.1029/2010WR009922, 2011.

Wang, Q. J., Robertson, D. E., and Chiew, F. H. S.: A Bayesian joint probability modeling approach for seasonal forecasting of streamflows at multiple sites, Water Resour. Res., 45, W05407, doi:10.1029/2008WR007355, 2009.

Yang, L., Tian, F., Sun, Y., Yuan, X., and Hu, H.: Attribution of hydrologic forecast uncertainty within scalable forecast windows, Hydrol. Earth Syst. Sci., 18, 775-786, doi:10.5194/hess-18-7752014, 2014. 